\title{
Enhancing standardisation and digital management of wind power
}

\author{
Junliang He ME \\ Senior Engineer, Longyuan (Beijing) Carbon Asset Management \\ Technology Co., Ltd, Beijing, China (hejunliang@sohu.com)
}

With the rapid development of wind power, various problems have emerged gradually in the operation and maintenance of wind farms. Most wind farms remain at the level of breakdown maintenance; it is difficult to provide a good solution, relying on traditional operation and maintenance. This paper proposes the substitution of foreseen prediction, technical supervision and preventive maintenance for traditional breakdown maintenance, through enhancing the standard and digitised management of wind power. The availability of informationalised and intelligentised methods would enable the building of trouble-free wind farms, improve the management level of wind power and promote sustainable and healthy development of wind power.

\section{Introduction}

Standardisation and digitisation are the foundation of the informationalised operation and maintenance of wind farms. The construction of a digital system is key to the informationalised operation and maintenance of wind farms. Use of big data technology and intelligent wind farms can guarantee the informationalised operation and maintenance of the wind farms (DL/T 793-2012 (CEC, 2012); Chi et al., 2020).

Wind power is characterised by many wind farm units, a variety of models and the complex configuration of the same type of components, leading to a large number of statistics on site. There are fewer workers in wind farms but each person plays multiple roles, which makes it difficult to spot equipment problems in advance (Adewuyi et al., 2019; Wettervik et al., 2020). The existing information systems are independent of each other (see Figure 1), and there is no resultant force at the system level. The centralised monitoring platform does not have the ability to effectively analyse and manage mass production data. There is a lack of communication among machine manufacturers, operators and third-party operation and maintenance (Dias and Kapetanios, 2018). The goal in this research study is to make use of an information management platform to build a digital wind farm characterised by electronic operation tickets, remote video security supervision, intelligent maintenance and fault diagnosis, digital data information, a networked communication platform and standardised information sharing. Digital technology is used to acquire, process, exchange and integrate all kinds of equipment information and production process information in the wind farm, including various models. The fan monitoring, booster station monitoring and wind field advanced comprehensive application are integrated on the whole wind field digital communication platform. Through true seamless real-time data sharing, the wind farm safety operation and maintenance management are achieved. And the wind farm operation and maintenance informatisation is realised with the support of a group-level cloud computing centre system (Ananth and Nagesh Kumar, 2017). The main tasks are to strengthen the generating capacity of units, to reduce the energy consumption of wind farms and to optimise unit planned downtime. Then optimise the maintenance and repair strategy, improve the maintenance capacity and reduce the unit fault maintenance downtime. In addition, the reliability of the unit would be improved and the failure frequency and the loss of spare parts would be decreased. The timeliness of spare parts supply would be improved and the spare parts inventory can be planned and arranged. The unit safety accident rate and the cost of safety inspection and investigation could be reduced. The efficiency of unit detection and supervision could be improved and the detection cost reduced (Li et al., 2013).

\section{Foundation of informatised operation and maintenance - construction of wind power normalisation and standardisation system}

Normalisation and standardisation management are the basis of informatisation of wind farms. The statistical calibre of operation should be standardised by means of an informatisation platform, including the construction of data consistency, the standardisation of artificial data management, the standardisation of the management process and the division and unification of the equipment reliability status (Liang, 2013; Zhang, 2016).

With the help of the information management platform, a digital wind farm with the basic features, such as electronic 


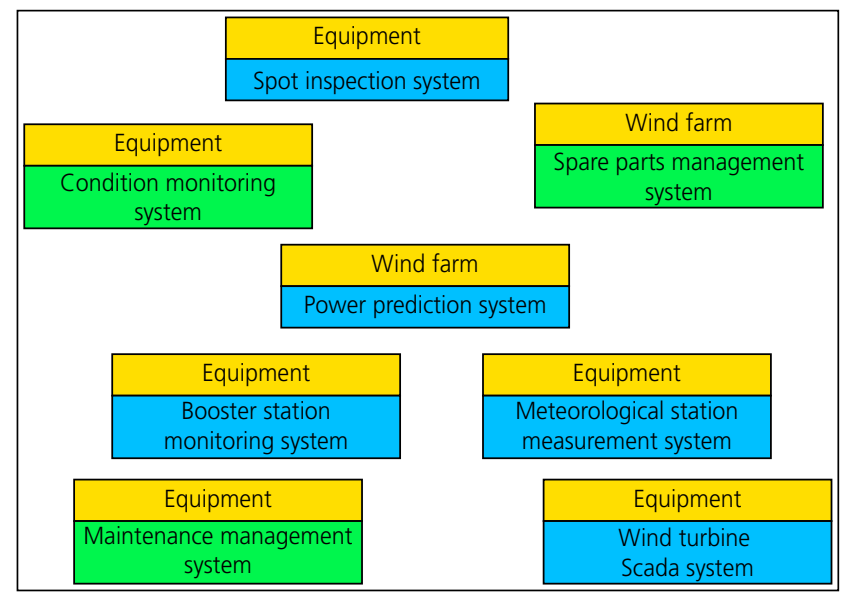

Figure 1. Diagram of information isolated island. Scada, supervisory control and data acquisition

operation tickets, remote video security supervision, intelligent maintenance and fault diagnosis, digital data and information, a networked communication platform and standardised information sharing, is built ( $\mathrm{Li}$ and Fang, 2018).

Digital technology is used to acquire, process, exchange and integrate all kinds of equipment information and production process information in the wind farm, including various models. The fan monitoring, booster station monitoring and wind field advanced comprehensive application are integrated on the whole wind field digital communication platform. Through true seamless real-time data sharing, the wind farm safety operation and maintenance management are achieved. And the wind farm operation and maintenance informatisation is realised with the support of a group-level cloud computing centre system (see Figure 2).

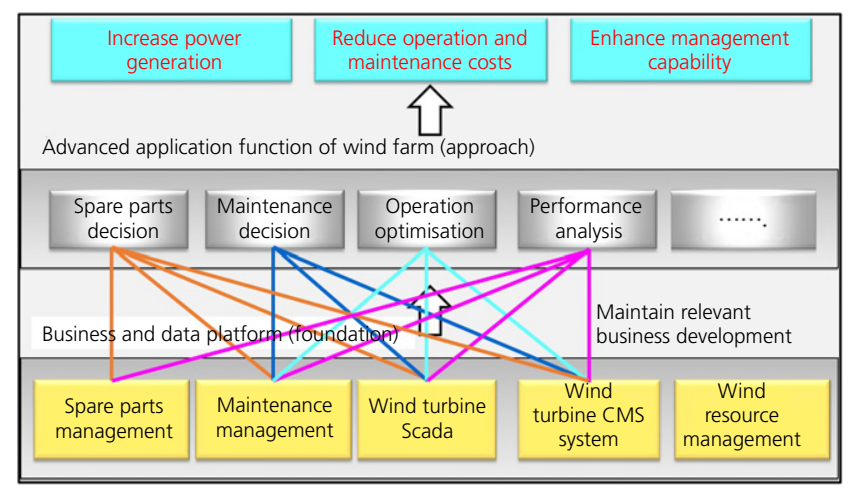

Figure 2. Diagram of system-level planning. CMS, condition monitoring system

\subsection{Data consistency construction}

The equipment in, and manufacturers of, the wind turbines, the booster station and substation are different, and the definitions of the measurement point are not the same. Therefore, the data measuring point information of different standards will be a major obstacle to wind farm informatisation (Endrenyi and Anders, 2006; Rogers et al., 2010). It will be the first and key work to carry out the digitisation, informatisation and intelligentisation of wind power plants to define and standardise the data of each piece of equipment (Wang et al., 2010). For example, the metering point of the wind field electric quantity meter should be clarified to ensure the unity and consistency of data sources. The unified operation statistics include the wind speed, the power generation collection point, the data interface, the fan timing, the time statistics and so on.

Example 1: measurement point of wind turbine generating capacity (Figure 3 ). In the industry, some measuring points for wind turbine generating capacity are located on the power generation side (reading from supervisory control and data acquisition (Scada), most of the collecting points are at the outlet of the converter, before the low-voltage side of the box transformer, excluding the self-consumption at the time of power generation). Others are located on the power gathering line.

The electricity quantity read from the Scada on the power generation side faces the problem of statistical accuracy. Undoubtedly, during the normal operation period, the amount of electricity generated by power generation operators is definitely different to the statistics from the electrical circuit side and power grid side (Samrout et al., 2009). The power generation of the fan metered by the electrical circuit has actually removed the power consumption of the fan, the loss from the box-type substation and the collector line. Thus, the statistical value is too small to truly reflect the power generation of the fan and the power consumption of the plant. Some of the early units, due to the consumption of electricity not having been removed, have high measured values of power generation and field electricity, resulting in not being comparable with other units. The above problems impact the accuracy of data statistics, the fairness of the subject and the consistency of information (Arshad and Islam, 2006; Bull et al., 2005).

Ideas and suggestions include the following.

(a) It is recommended to unify the measurement points of the wind farm power generation on the power generation side, not the collector line side or the grid side. 


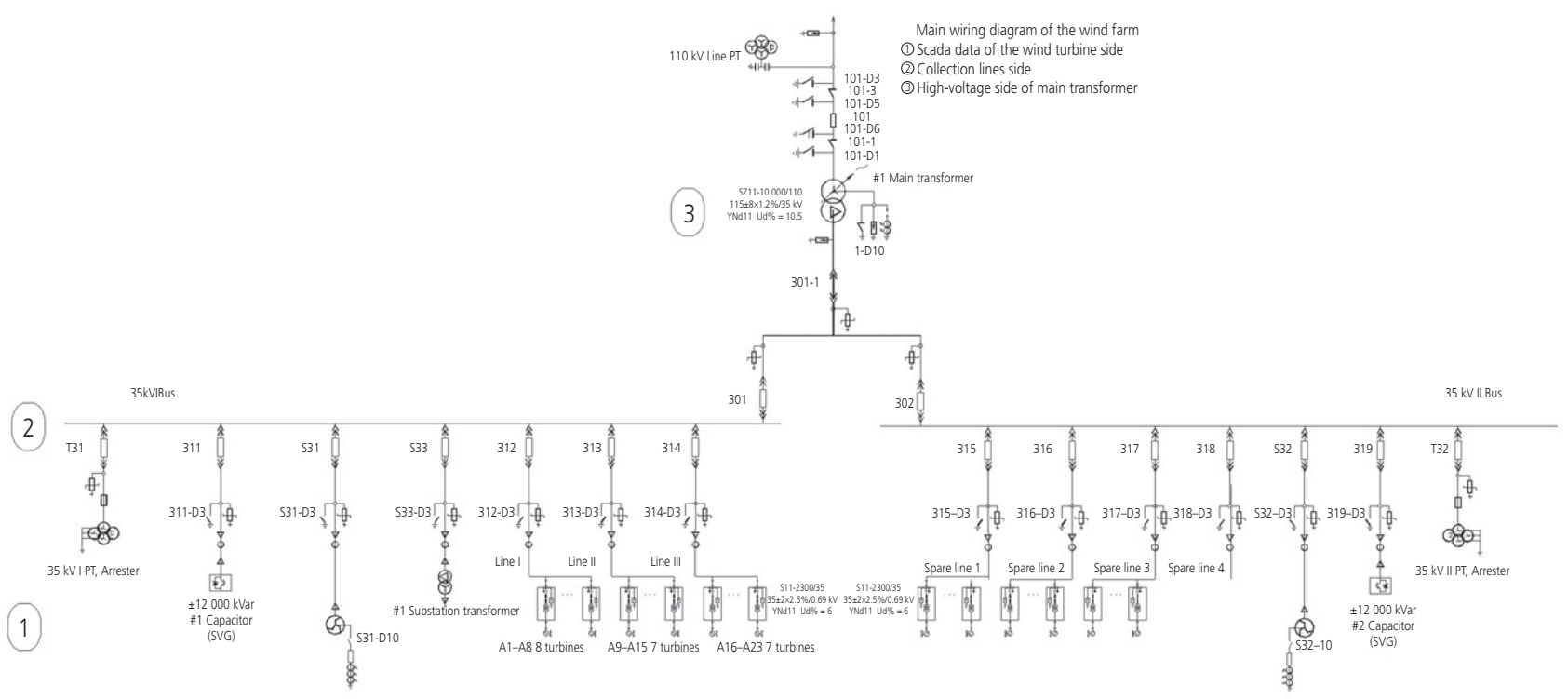

Figure 3. Main wiring diagram of the wind farm

(b) Under the existing conditions, the solution to the Scada reading accuracy problem is as follows:

(i) developers and manufacturers work together to strengthen the Scada specification to make data authentic and reliable

(ii) strengthen Scada maintenance to ensure data validity and continuity.

(c) Gradually renovate and install an electric energy meter that meets the accuracy at the specified metering point to meet the needs of statistics and benchmarking management.

(d) In the future mainframe contract, clear technical requirements should be put forward for the power generation metering device of the fan to meet the uniformity demand.

\subsection{Standardisation management of artificial data}

(a) Definition of artificial data: according to the sources of wind power operation and maintenance data, the whole wind power data can be divided into two categories.

(i) Machine data: collected automatically by each information system, and no personnel are required to participate in the collection process, such as receipts collected by Scada and data collected by online vibration detection.

(ii) Artificial data: data generated by personnel activities and manually input by personnel to enter the system, such as regular maintenance data, point inspection data, overhaul and technical improvement data, data on receipt and return of spare parts, fault processing data and so on.

Artificial data are an important part of the basic data of wind power. If this part of the data cannot be digitised and enter into the system smoothly, the informatisation and intellectualisation of wind power operation and maintenance will be incomplete and even impossible to be realised.

(b) The standardisation of artificial data.

Example 2: electronic operation of work tickets. Work tickets and operation tickets are completed through the control of process in the system. These historical records are automatically recorded for inquiry, in order to realise the normalised, paperless and automated wind farm operation and management. If the paper work ticket is used, it takes about $40-50 \mathrm{~min}$ from the beginning of filling the ticket to the beginning of execution. If the electronic ticket is used, it only takes about 10-20 min, which greatly reduces the workload and makes the artificial data enter the system relatively completely.

\subsection{Standardisation of management processes}

Example 3: closed-loop management of defects.

(a) Generally, equipment defects can be divided into the following three categories.

(i) General defects: have little impact on the safe operation of the equipment, and can maintain their nameplate rating to continue to operate, according to the degree allowed to be included in the daily, 
monthly, quarterly (annual) maintenance plan to arrange to deal with the defects.

(ii) Emergency defects: refers to any defect that seriously threatens the safety of humans and equipment, may cause an accident at any time and seriously affects the continuous operation of equipment, and must be dealt with in time.

(iii) Major defects: refers to a defect that has an impact on the service life or handling of the equipment, or may develop into an emergency defect, but allows short-term operation or follow-up analysis.

(b) Closed-loop management process of defects, shown in

Figure 4. Requirements of closed-loop management procedures are as follows.

(i) Invoice must be issued to eliminate no-ticket operation, as no-ticket operation has been identified as a defect.

(ii) Eliminate defects in an orderly manner according to the defect level.

(iii) The executors of defects and hidden dangers of each link cannot take part-time jobs or replace each other, and the most important thing is that the executor, acceptor and safety supervisor, who eliminate defects and hidden dangers in each link, cannot substitute for each other. The executor is responsible for the operation. There should be an acceptance process after the completion of the implementation. The safety supervisor ensures the safety of all people and the completion of the task.

According to the above requirements, the standardisation process is compiled to eliminate ticket-free operation and to carry out operation and maintenance in an orderly and closedloop manner (Diederik et al., 2007).

\subsection{Standardisation management of equipment reliability}

(a) Basic status division of the industry. The problem of reliability arises and develops with the need of the

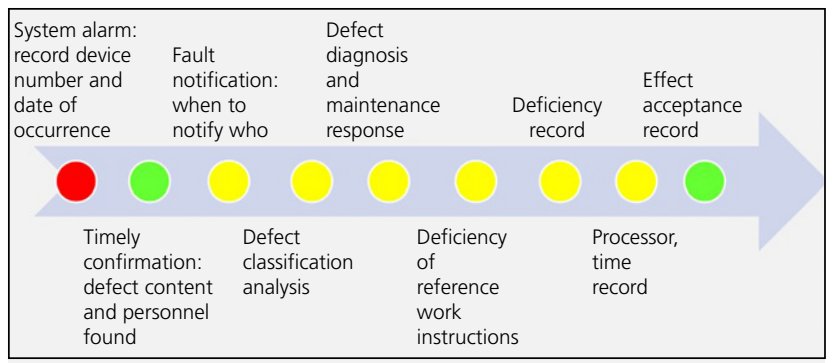

Figure 4. Closed-loop management process of defects objective situation on the basis of social practice. Currently, the reliability discipline has penetrated into various industrial sectors, and reliability has become an important symbol of product quality index and product competitiveness. Although the reliability method originated from the military field, with the progress of society and the development of science and technology, the reliability method has been fully developed and applied to all sectors and fields of the national economy. Its creation and development are required by society, and the development of science and technology is inseparable. Status classification of equipment reliability is shown in Figure 5.

(b) According to the equipment classification, the criteria for unavailable state of wind farms are shown in Figure 6.

(c) According to the status classification and data mining system, nine loss statuses are show in Figure 7 for the loss link of power generation.

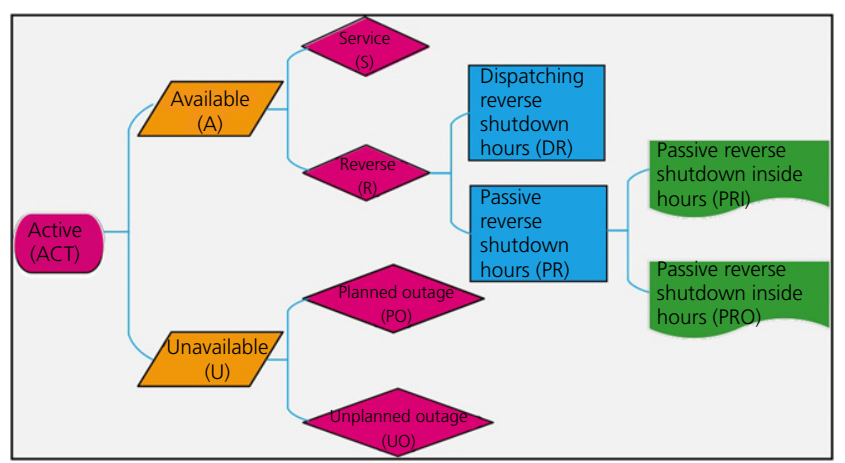

Figure 5. Equipment reliability status classification

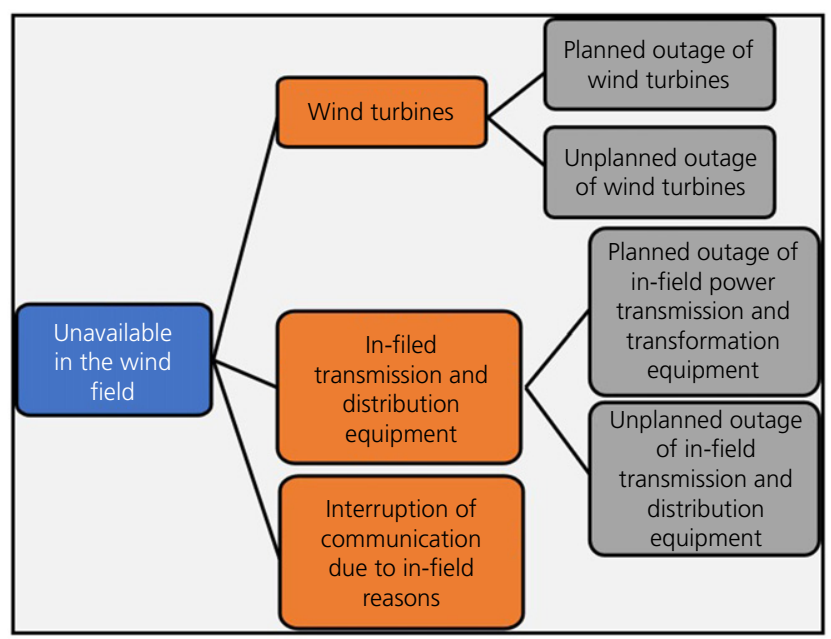

Figure 6. Unavailable status classification of wind farms 


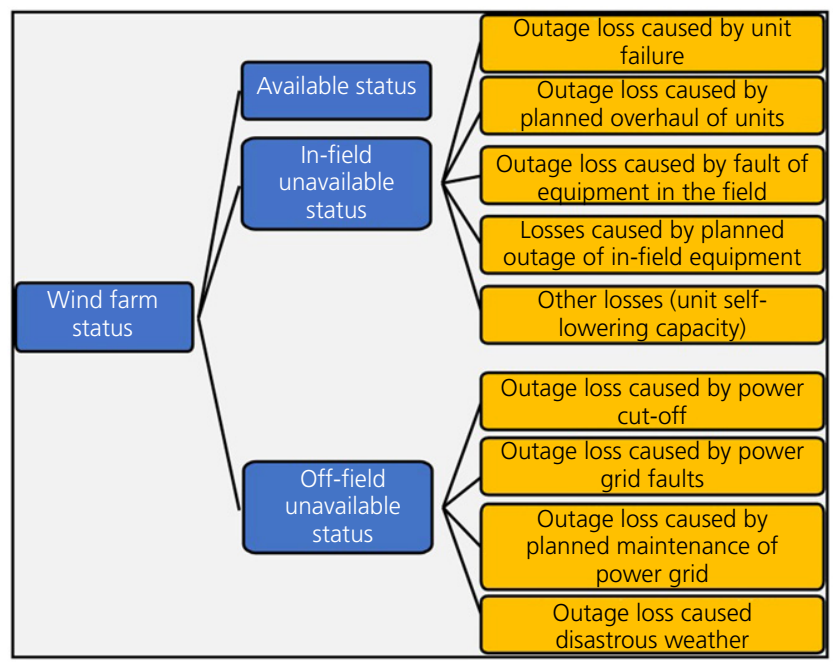

Figure 7. Classification of wind farm loss status

By standardising the operation status identification and data recording of the unit, it is possible to accurately calculate the theoretical power generation, and then realise the detailed decomposition of the lost power through the system and analyse various loss statuses in depth.
The standardisation made the cause of original fuzzy power loss clear, clarified the improvement space and direction of the unit and directed the fine maintenance and optimisation of the inspection mode, which promoted the innovation of the system and digital progress (Sofiane et al., 2003).

\section{Key of informatised operation and maintenance: construction of digitisation system}

\subsection{Build a digitised wind farm}

The key technologies for creating digital wind farms include the following.

(a) Establish unified monitoring management of wind farm (Figure 8). Real-time data collection, processing, storage, display, as well as automatic generation control, automatic voltage control, equipment control and other functions, automated reports. Complete production data consistency building. Establish the wind field monitoring and management system based on the International Electrotechnical Commission standard.

(b) Establish primary equipment status data collection. Through the technical means of unit vibration, oil monitoring and digital transformation of electrical primary equipment, the data of key equipment are

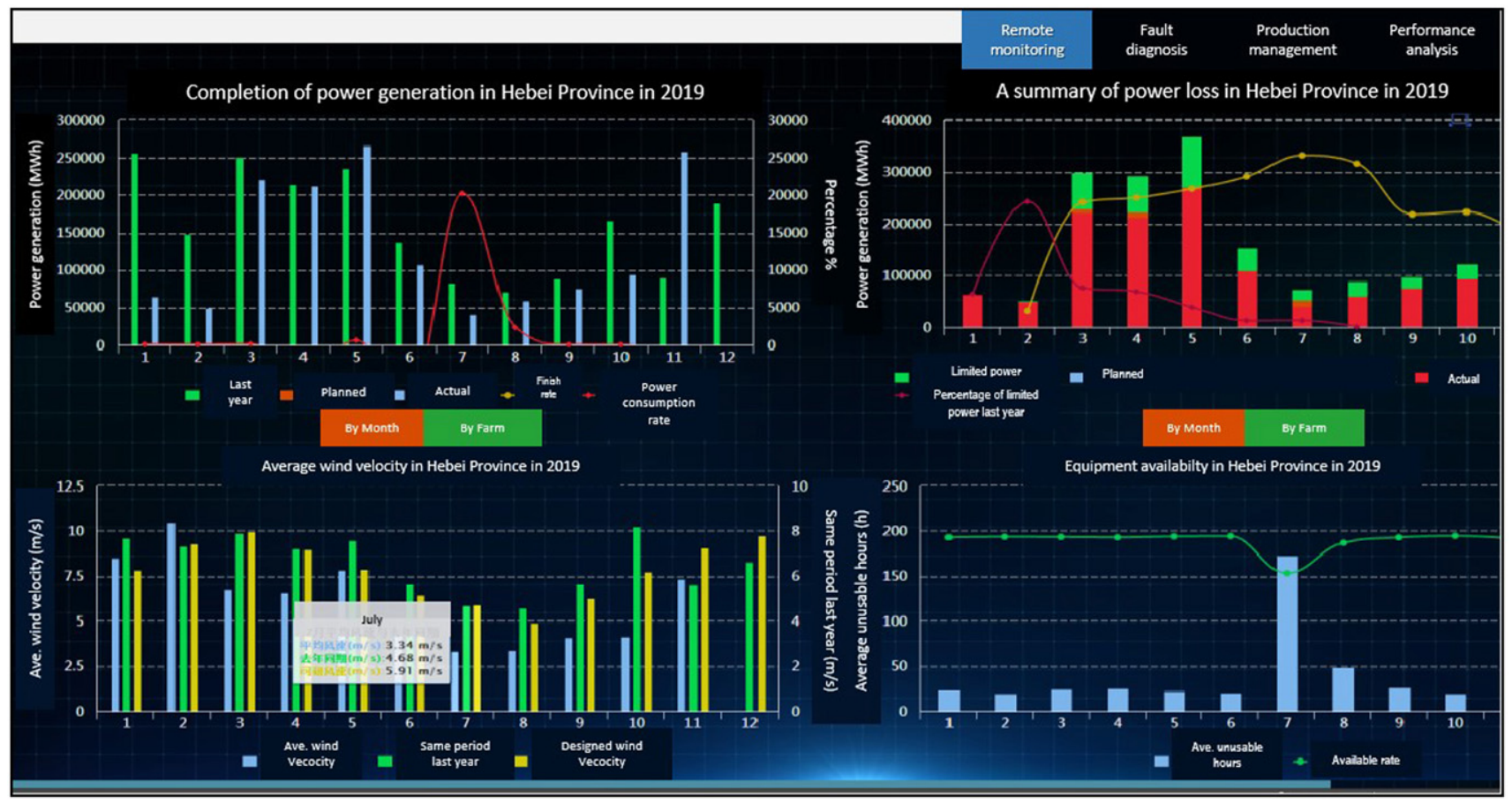

Figure 8. Example of the unified monitoring management of a wind farm 
collected and transmitted to the regional production and operation centre and the remote state diagnostic centre.

(c) Establish video surveillance and intelligent inspection.

Through the installation of cameras in key parts of the wind farm, the monitoring of the field and equipment can be realised. Through the spot check system, continue the effective management of the maintenance personnel's regular patrol inspection.

(d) Establish environmental monitoring and power prediction of wind farm power (Figure 9). Numerical weather forecast and micrometeorological information monitoring are used to give early warning of severe weather. Based on the fusion technology of data assimilation and numerical weather prediction system, a wind farm power prediction service system is constructed.

(e) Establish digitised duty. Based on the equipment parameters, the system can automatically handle the soft fault of the unit without notifying the maintenance personnel of the fault.

( $f$ ) Develop an auxiliary maintenance system based on a mobile terminal. A maintenance assistance system is developed based on a mobile terminal, so that maintenance personnel can obtain the remote expert diagnosis centre fault solution in real time, and record the maintenance process to improve the maintenance efficiency.

(g) Realise the automation of production management. To realise the functions in production operation management, including shift, tools, key management, production report, work ticket, operation ticket, remote electronic work ticket, automatic data statistics and other functions.

\subsection{Establish centralised control centre for digitised regional production and operation}

Based on secure private network communication, realise remote centralised control and management of the wind farm. This mainly includes the following.

(a) Remote monitoring platform. Monitor the production and operation of all equipment of the wind farm in the area.

(b) Production management platform. Synchronise with the wind field data to achieve electronic work tickets,

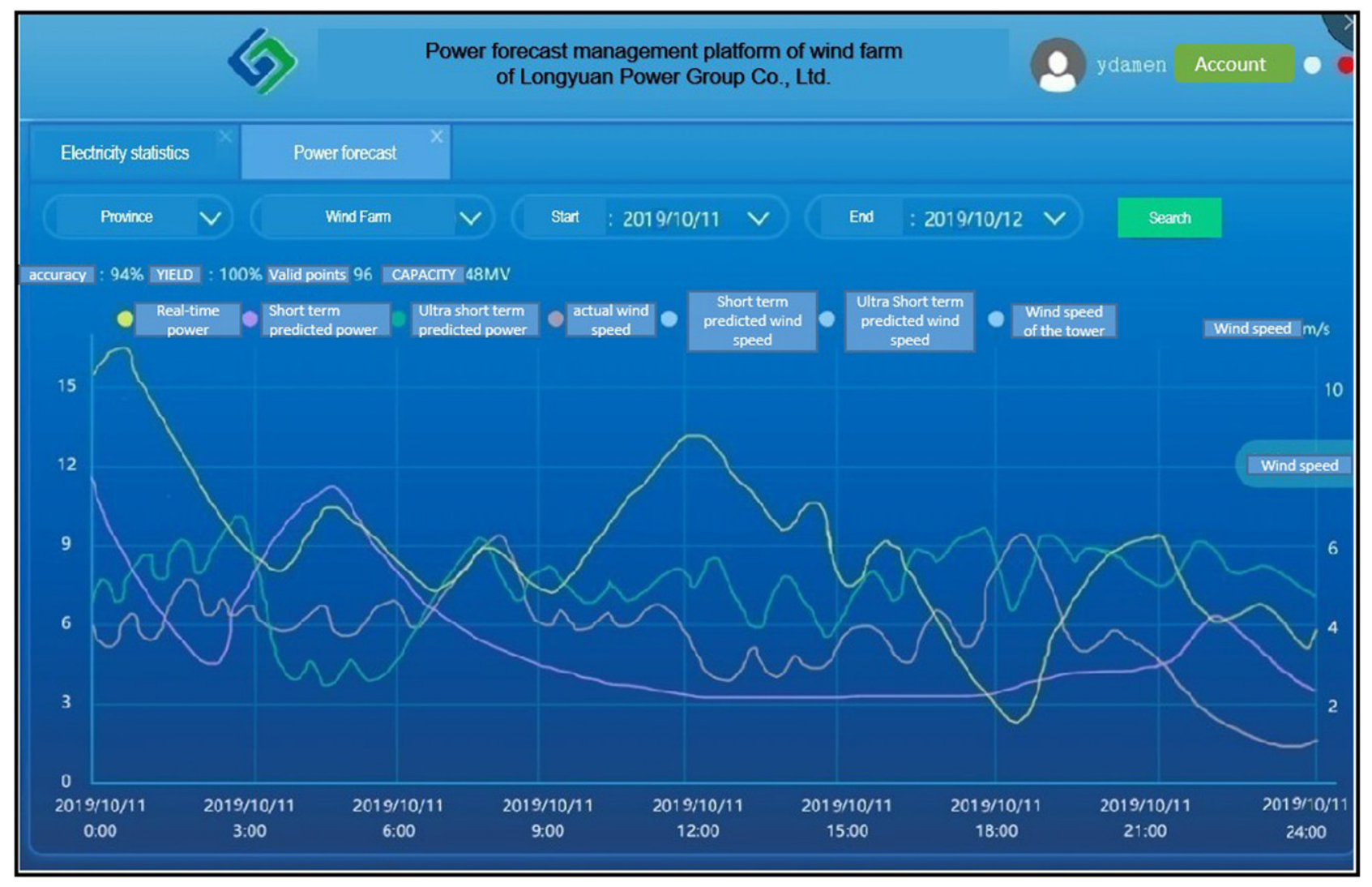

Figure 9. Example of the environmental monitoring and power prediction of wind farm power 
data collection, automatic report and production management.

(c) Asset management platform. Manage assets of the wind farm and establish the full life equipment ledger according to unified standards.

(d) Data analysis platform. Make a mining analysis of the power generation performance of each wind farm.

(e) Status diagnosis platform. Based on condition monitoring, make diagnosis and early warning of key equipment such as unit, main transformer and so on.

\subsection{Build the private cloud: group-level cloud computing centre}

On the basis of device virtualisation and task assignment scheduling technology, the storage of massive amounts of data is achieved, a private cloud is established and the following functions are realised.

(a) Production monitoring centre: monitoring and managing key production parameters of regional companies of the group. (b) Production management centre: collecting regional production data, realising the sharing of information about data and spare parts, standardising management and unifying scheduling.

(c) Performance analysis centre: based on data mining and other technologies, analysing the power generation performance of a wind turbine generator.

(d) Expert diagnosis centre: helping the wind farm solve difficult and complicated problems through a collaborative diagnosis platform, and improving the utilisation rate of equipment.

\subsection{Realisation of informatised operation and maintenance: provide support for fine maintenance of equipment}

The characteristics of fine maintenance are preventive maintenance and individualised maintenance. To achieve preventive maintenance, it is necessary to discover the hidden danger of the unit; and to achieve individualised maintenance, each unit should be treated with the right and proper method. All of these need information collection and accumulation,

Table 1. Detailed data analysis before fine maintenance

\begin{tabular}{|c|c|c|c|c|c|}
\hline \multicolumn{6}{|c|}{ Description of historical faults and historical alarm of Faku East Wind Farm 12\# unit; responsible person: Liu Qiang } \\
\hline Number & Frequency level & Code & \multicolumn{2}{|l|}{ Description } & Key inspection \\
\hline 1 & & 100 & \multicolumn{3}{|c|}{ Yaw sensor faults } \\
\hline 2 & & 118 & \multicolumn{3}{|c|}{ Yaw motor errors } \\
\hline 3 & & 411 & \multicolumn{3}{|c|}{ High temperature of brake } \\
\hline 4 & & 416 & \multicolumn{3}{|c|}{ Vibration sensor alarm } \\
\hline 5 & & 2118 & \multicolumn{3}{|c|}{ Interbus bus errors } \\
\hline 6 & & 3229 & \multicolumn{3}{|c|}{ High bus voltage of software detection } \\
\hline 7 & & 3238 & \multicolumn{3}{|c|}{ Ultralimit of frequency difference of rotating speed of generator in delta connection } \\
\hline 8 & & 3612 & \multicolumn{3}{|c|}{ Tripping of medium voltage switch } \\
\hline 9 & & 410 & \multicolumn{3}{|c|}{ Over-speed protection device action } \\
\hline 10 & & 210 & \multicolumn{3}{|c|}{ No release of high-speed brakes } \\
\hline \multicolumn{6}{|c|}{ Description of historical faults and historical alarm of Faku East Wind Farm 35\# unit; responsible person: Liu Siyuan } \\
\hline Number & \multicolumn{2}{|c|}{ Frequency level } & Code & Description & Key inspection \\
\hline 1 & & & 3406 & External fans and electromagnetic brake feedback alarm & \\
\hline 2 & & & 3311 & High temperature of busbar & \\
\hline 3 & & & 3415 & Disconnection of stop loop & \\
\hline 4 & & & 118 & Yaw motor errors & \\
\hline 5 & & & 3410 & Disconnection of FG008 & \\
\hline
\end{tabular}




\section{Energy}

Volume 174 Issue 2
Enhancing standardisation and digital

management of wind power

$\mathrm{He}$

Table 2. Formulate higher and more comprehensive maintenance standards based on data analysis and applying remedies according to indications

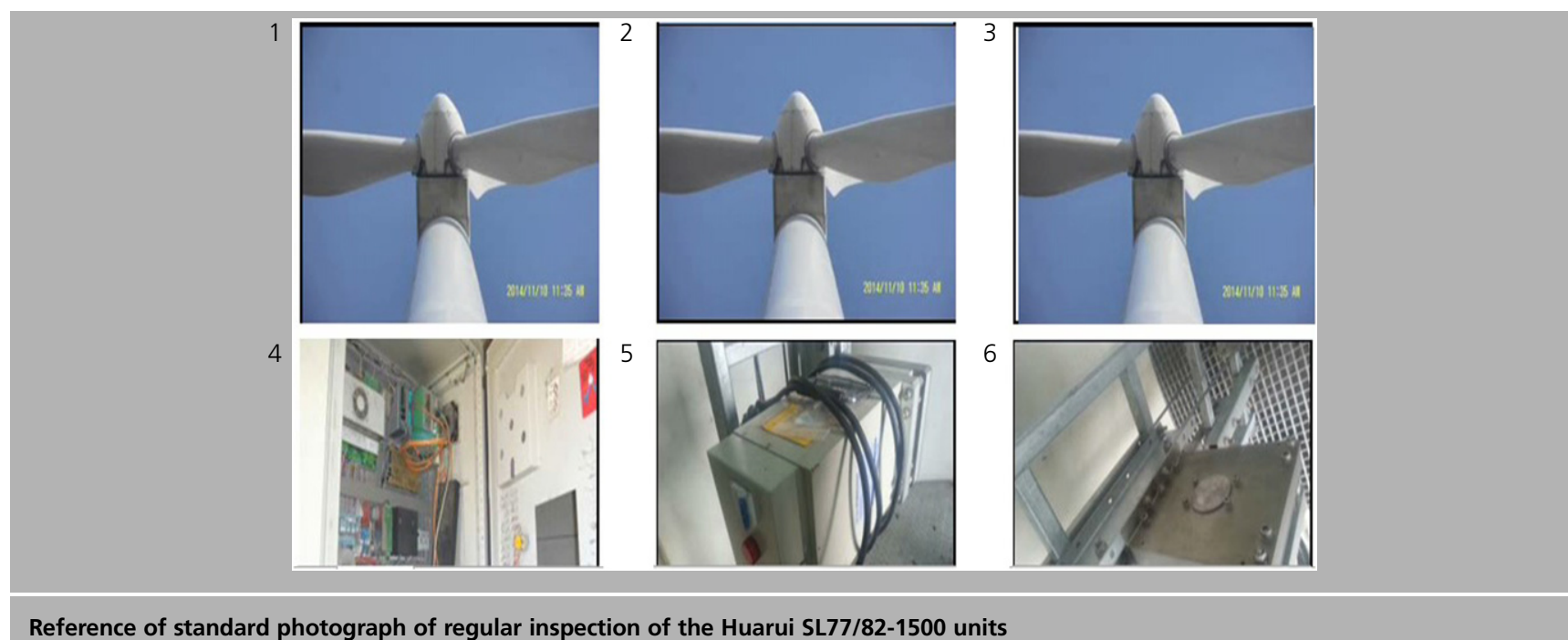

(1) Visual inspection of blade appearance

No crack, corrosion and lightning damage are detected by telescope. The sealing between root flange and blade shell is good

(4) Mounting bolts on root cover plate of the blade

There are no loose bolts, and the sealing is good
(2) Check the running noise and internal sundries of the blade

When the blade rotates at low speed, there is no rolling sound in the blade; when the speed of the generator reaches $1200 \mathrm{r} / \mathrm{min}$, there is no abnormal sound in the blade.

(5) Mounting bolts on blade/variable oar bearing

ROCOL 10025 lubrication tyre is adopted, with HT34 blade/1100 N m and other blades/1250 N m. MOLYKOTE lubrication tyre is adopted, with $1000 \mathrm{~N} \mathrm{~m}$.
(3) Check lightning protection system

The grounding wire is well insulated and the bolt is not loose

(6) Visual inspection of the appearance of pitch bearing

There is no oil pollution, and anti-corrosion and sealing is good. Nozzle and oil-receiving bottle are intact. Lightning-proof carbon fibre brush is intact.
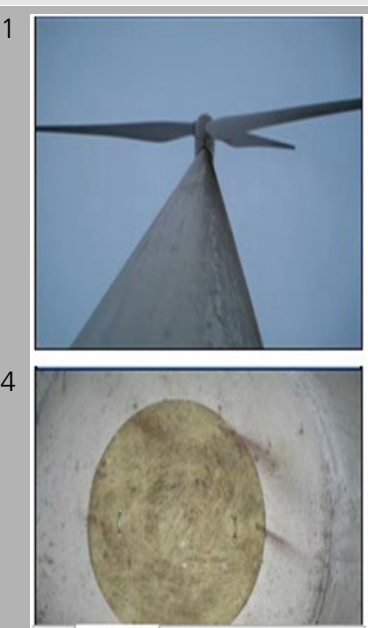

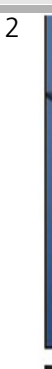

5

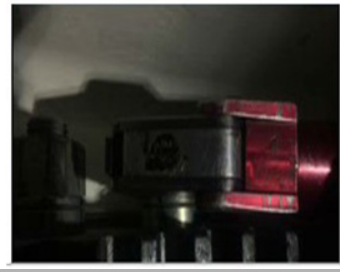

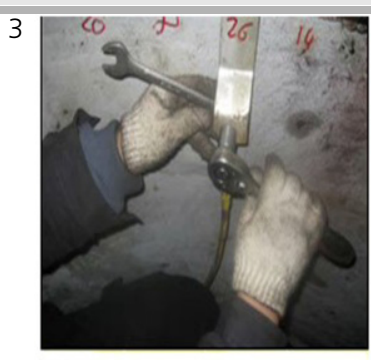

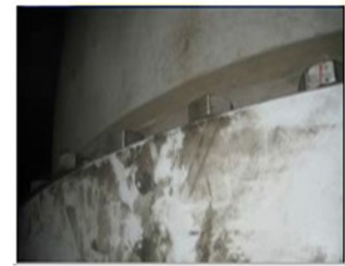

Gamesa reference of standard photograph of regular inspection of Gamesa units

(1) Listen and check the start-up noise of each blade

(4) Check the area of the bottom electrical cabinet, clean the ash and tighten the wires; check the pressure of the fire extinguisher and record it
(2) Listen and check whether there is noise from the mechanical parts when each blade rotates

(5) Check and confirm the operation of the crawler
(3) Visually inspect the blades and specify sequence standards of three blades; facing the impeller direction under the tower and based on the lifting hole, and the counter-clockwise order shall be '1,2,3'.

(6) Visual inspection of anchor points of crawler 


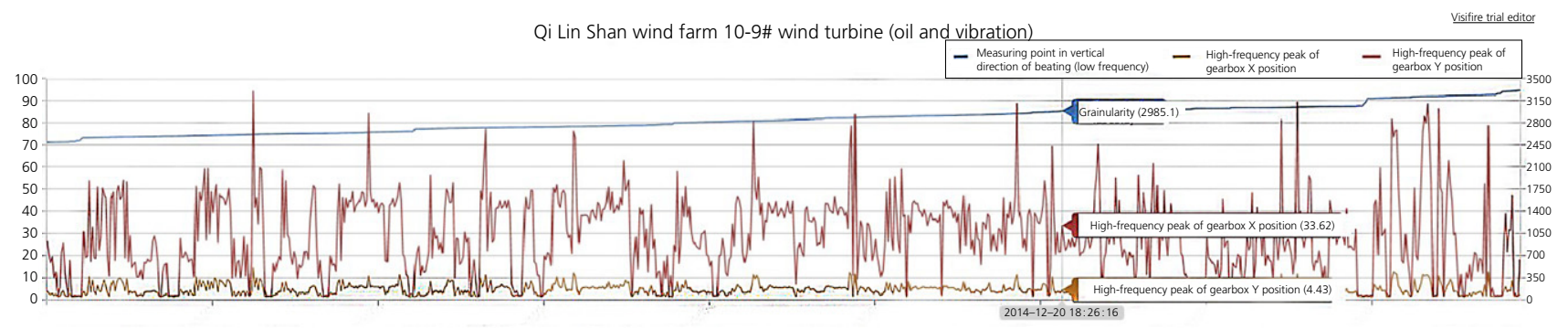

Figure 10. Diagnosis platform of oil and vibration

which is the purpose of informationalised operation and maintenance.

Example: case of fine maintenance of wind farms (Tables 1 and 2).

\subsection{Realisation of informatised operation and maintenance: provide an effective scheme for equipment performance optimisation}

Through the mining of historical data and vertical and horizontal comparison, the problems of the unit can be exposed quickly, so that the user can know how to optimise it.

Through the collection of wind turbine mass production and operation data, using artificial intelligence, machine learning and other advanced algorithm technology, the data are further analysed. By using comparative analysis of key performance indicators (KPIs), the potential failures, performance defects and other sub-health elements of the state of the unit are detected, and an equipment defect analysis report is provided. Through the analysis of the wind turbine power curve, the abnormal control and substandard performance of wind turbine can be caught. The unit performance is optimised by means of anemometer and vane calibration to improve the efficiency of power generation on the site. In terms of vibration monitoring, the project construction focuses on wind turbine parameters and vibration detection. Through the study of the mechanical transmission chain of the wind turbine, the data related to the operation state of the wind turbine are collected. At the same time, the remote diagnosis centre is established, and the functions of data processing and diagnosis analysis of the remote diagnosis system are combined, so that the operation status report of the equipment can be given for warning before the fault occurs. In terms of oil monitoring, the project focuses on the study of gear oil state parameters. Through the independent research and development of a set of oil metal particle count sensors, the underlying hardware circuit design can be studied. At the same time, a remote diagnosis centre based on oil information and vibration information can be established to give the

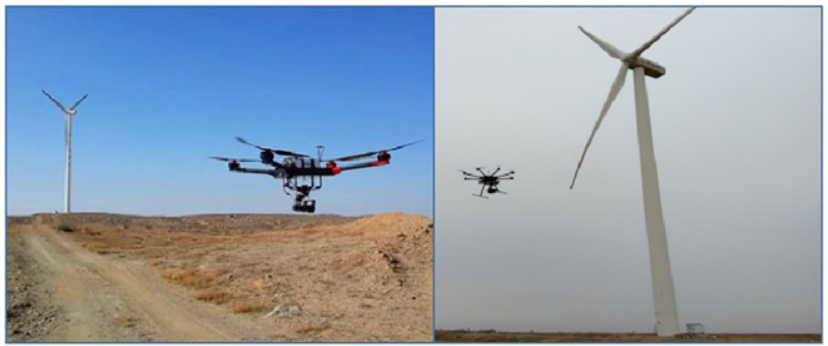

Figure 11. Inspection of blades using a UAV

operating status report of the equipment for warning before the fault occurs (Figure 10). In terms of unmanned aerial vehicle (UAV) detection, the project adopts the method of replacing the traditional blade monitoring with an unmanned vehicle (Figure 11). A UAV is used to carry out the inspection of fan blades, and take high-definition photographs and video of typical fan blades in both infrared and visible light.

\subsection{Informatised operation and maintenance: make unattended and fault-free wind farms possible}

Fault-free wind farms require reliable equipment and can predict some events affecting the equipment. In addition to the requirements for equipment reliability, unattended wind farms also require monitoring of the comprehensive information of the equipment.

Through the construction of centralised monitoring and comprehensive sensor installation, the unit state information could be captured fully. In addition, front-line personnel can carry out effective monitoring of on-site equipment. Through the fault early warning system, equipment abnormalities can be automatically caught. The work order could be automatically triggered, and the maintenance personnel could deal with the fault and eliminate the loss using the management system. To achieve the safety control of unattended wind farms, the first thing is to improve the site infrastructure conditions. The 
network coverage construction and video construction of booster stations and units in wind power plants will be the necessary link to realise unattended wind power plants.

\section{Conclusions}

\subsection{Significance of informatisation and intelligentisation construction}

According to the characteristics of massive data volume and partial functional computing volume in the wind power industry, big data and cloud platform technology are adopted to realise integrated management from the early stage through infrastructure construction, production and operation and post-evaluation. Based on the traditional production and operation monitoring centre, wind power operators carry out research on the comprehensive analysis method of wind power generation benefits by improving, transforming and upgrading, and using the actual operation data, so as to realise the calculation of wind power generation capacity and the analysis of all kinds of power losses. Through the detailed analysis of the causes of electricity loss and the degree of influence, the key factors affecting power generation are identified. The fine management and improvement work are carried out. The post-evaluation technology of wind farm depth is implemented, and the distribution of wind resources in wind farms is comprehensively analysed by means of virtual wind measurement and so on, and the blind spots of early planning are explored to optimise the design of wind farms.

\subsection{Function of informatisation and intelligentisation construction}

(a) Set up a large database to reduce all kinds of errors and improve the level of delicacy management.

(b) It can realise the safe, reliable, efficient and economical operation of wind power equipment, and realise the life-cycle management of the equipment.

(c) It can accurately calculate the energy utilisation rate, adjust the wind field mode in real time, reduce the loss of electricity and realise energy management.

(d) Improve the maintenance process level and effectively reduce the electricity loss and the cost of operation and maintenance caused in the field.

(e) Reduce the repetitive workload of operation and maintenance personnel and lower the labour risk of operation and maintenance personnel.

( $f$ ) With the help of the internet of things, big data, cloud computing, the automatic acquisition, collection, classification, statistics, mining of data and acquisition of valuable information are realised, which provides the basis for management and decision making.

\subsection{Informatisation and intelligentisation are the inexorable results of standardisation and digitisation development}

(a) Standardisation enables the computer system to identify the standardised data smoothly, and also makes the digitisation have the source of the data.

(b) Digitisation is to computerise the operation and maintenance data and automate some of the contents, so that a large amount of data can be stored and consulted, and the operation and maintenance personnel can make a quick comparative analysis. At the same time, the workload of the operation and maintenance personnel is lowered.

(c) With the development of computer technology and network technology as well as gradual accumulation of wind power data, obtaining useful data can not only guide the operation and maintenance personnel to provide the basis for decision making, but also predict the defects and faults of equipment to enable effective prevention to be carried out, which deeply implements the policy of 'safety first, prevention prime, comprehensive administration'.

\subsection{The prospect of the big data era}

Big data technology has gradually matured and improved in recent years. Big data analysis is just in line with the industry characteristics and problems of new energy power generation, and its analysis technology can meet the value demands of enterprises very well.

Data are the core asset of an enterprise, on which the future value creation and management promotion must be based. Technology might become obsolete, but data would not. It will be a solid foundation for promoting quality, efficiency and sustainable development of enterprises. Full dimensional digital modelling of wind power assets and total life-cycle information management based on big data will become the inexorable trend of the development of the industry.

\section{REFERENCES}

Adewuyi OB, Lotfy ME, Akinloye BO et al. (2019) Security-constrained optimal utility-scale solar PV investment planning for weak grids: short reviews and techno-economic analysis. Applied Energy 245: 16-30.

Ananth DVN and Nagesh Kumar GV (2017) Mitigation of voltage dip and power system oscillations damping using dual STATCOM for grid connected DFIG. Ain Shams Engineering Journal 8(4): 581-592.

Arshad M and Islam SM (2006) A novel fuzzy logic technique for power transformer asset management. In Conference Record of the 2006 IEEE Industry Applications Conference Forty-First IAS Annual Meeting. IEEE, Piscatway, NJ, USA, pp. 276-286. 
Bull JD, Jaeger NAF and Rahmatian F (2005) A new hybrid current sensor for high-voltage applications. IEEE Transactions on Power Delivery 20(1): $32-38$.

CEC (China Electricity Council) (2012) DL/T 793-2012: Reliability evaluation code for generation equipment. Power Industry Standard, China Electricity Council, Beijing, China.

Chi RF, Liu L and Wang D (2020) Study on the stability of high-scale wind power system considering the wind farm cluster effect. Journal of Shenyang Institute of Engineering (Natural Science edition) 16(3): 13-18 (in Chinese).

Dias GF and Kapetanios G (2018) Estimation and forecasting in vector autoregressive moving average models for rich datasets. Journal of Econometrics 202(1): 75-91.

Endrenyi J and Anders GJ (2006) Aging, maintenance, and reliability-approaches to preserving equipment health and extending equipment life. IEEE Power \& Energy Magazine 4(3): 59-67.

Gasmi S, Love CE and Kahle W (2003) A general repair, proportionalhazards, framework to model complex repairable systems. IEEE Transaction on Reliability 52(1): 26-32.

Li G and Fang ZN (2018) Exploration on intelligent model of wind farm. New Energy: Electric Power System Equipment (4): 148-150 (in Chinese).

Li C, Shen Z, Meng KF, Bao DE and Yin S (2013) Computation method and analysis and comparison of wind turbine generation quantity. In Annual Conference on Informatization of Election Power Industry (Yin S, Li C, Shen Z, Meng KF and
Bao DE (eds)). Professional Committee of Electric Power Informatization of CSEE, Posts and Telecom Press, Beijing, China, pp. 226-228.

Liang H (2013) Discussion on operation and maintenance management of wind farm. Equipment Manufacturing Technology (5): 296-298 (in Chinese).

Lugtigheid D, Jardine AKS and Jiang X (2007) Research optimizing the performance of a repairable system under a maintenance and repair contract. Quality and Reliability Engineering International 23(8): 943-960.

Rogers J, Fink S and Porter K (2010) Examples of Wind Energy Curtailment Practices. Office of Scientific and Technical Information, Oak Ridge, TN, USA, Technical Report no. 984667.

Samrout M, Chatelet E, Kouta R and Chebbo N (2009) Optimization of maintenance policy using proportional hazard model. Reliability Engineering and System Safety 94(1): 44-52.

Wang Y, Wang H and He B (2010) Calculation of power equipment reliability for condition-based maintenance decision-making. In Proceedings of the 2010 International Conference on Power System Technology. IEEE, Piscatway, NJ, USA, pp. 1-7.

Wettervik TS, Howells T, Hillered L et al. (2020) Mild hyperventilation in traumatic brain injury - relation to cerebral energy metabolism, pressure autoregulation, and clinical outcome. World Neurosurgery 133: 567-575.

Zhang WB (2016) Simple analysis of wind farm operations management. Energy and Energy Conservation 126(3): 108-109.

\section{How can you contribute?}

To discuss this paper, please email up to 500 words to the editor at journals@ice.org.uk. Your contribution will be forwarded to the author(s) for a reply and, if considered appropriate by the editorial board, it will be published as discussion in a future issue of the journal.

Proceedings journals rely entirely on contributions from the civil engineering profession (and allied disciplines). Information about how to submit your paper online is available at www.icevirtuallibrary.com/page/authors, where you will also find detailed author guidelines. 